\title{
Behavioural test battery for the Back of the Brain project
}

\author{
Ro J. Robotham ${ }^{1 *}$, Sheila J. Kerry ${ }^{2}$, Grace E. Rice ${ }^{3}$, \\ Alex P. Leff ${ }^{2}$, Matthew A. Lambon Ralph ${ }^{3}$ \& Randi Starrfelt ${ }^{1 *}$
}

${ }^{1}$ Department of Psychology, University of Copenhagen, Denmark

${ }^{2}$ University College London Queen Square Institute of Neurology, UK

${ }^{3}$ MRC Cognition and Brain Sciences Unit (CBU), University of Cambridge, UK

*Corresponding authors: jer@psy.ku.dk; randi.starrfelt@psy.ku.dk

Keywords: Visual perception; Stroke; Neuropsychology 


\section{ABSTRACT}

Much of the patient literature on the visual recognition of faces, words and objects is based on single case studies of patients selected according to their symptom profile. The Back of the Brain project aims to provide novel insights into the cerebral and cortical architecture underlying visual recognition of complex stimuli by adopting a different approach. A large group of patients was recruited according to their lesion location (in the areas supplied by the posterior cerebral artery) rather than their symptomatology. All patients were assessed with the same battery of sensitive tests of visual perception enabling the identification of dissociations as well as associations between deficits in face, word and object recognition. This paper provides a detailed description of the extensive behavioural test battery that was developed for the Back of the Brain project and that enables assessment of low-level, intermediate and high-level visual perceptual abilities.

- Extensive behavioural test battery for assessing low-level, intermediate and high-level visual perception in patients with posterior cerebral artery stroke

- Method enabling direct comparison of visual face, word and object processing abilities in patients with posterior cerebral artery stroke

\section{GRAPHICAL ABSTRACT}

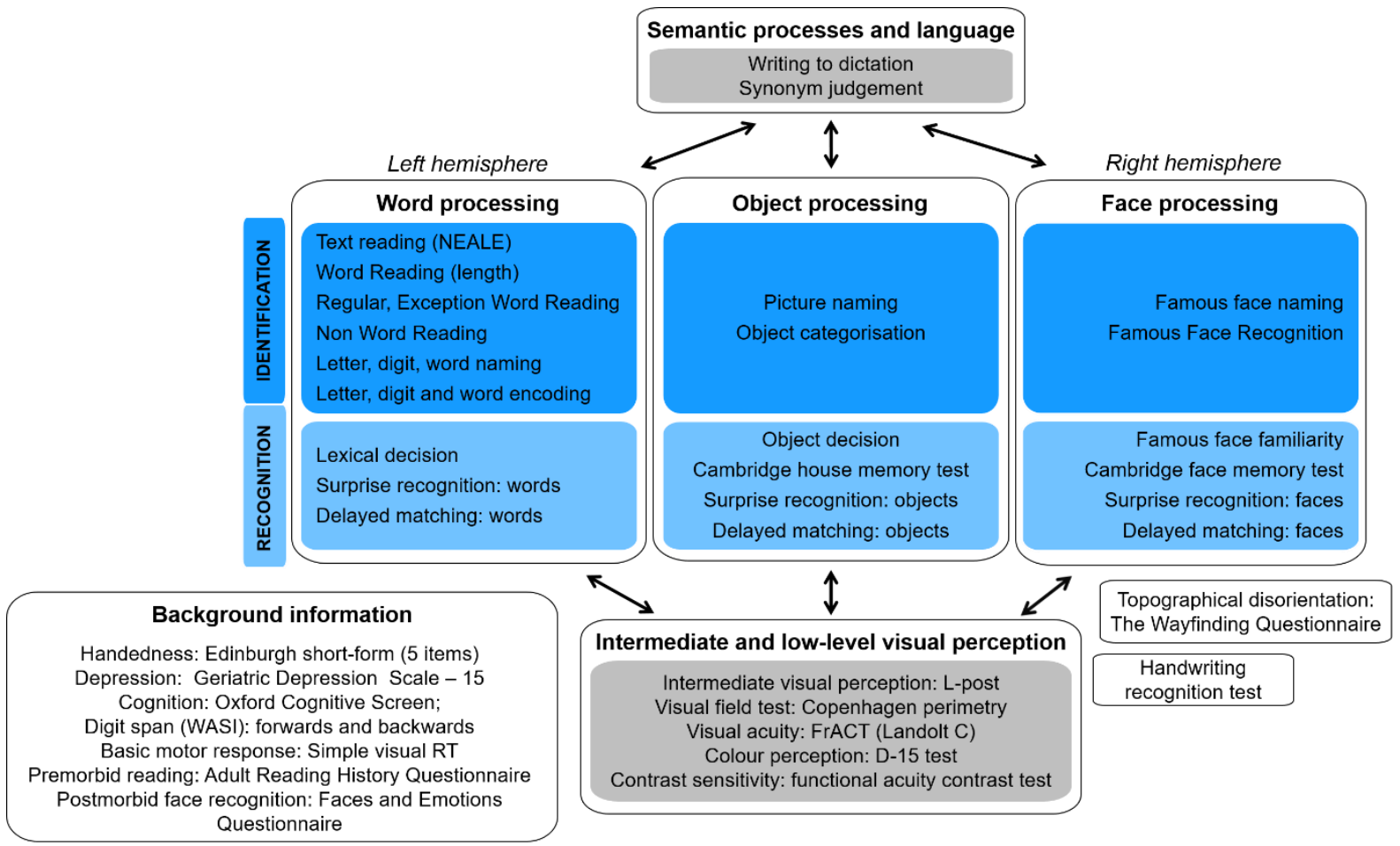




\section{Introduction}

The aim of the Back of the Brain $(\mathrm{BoB})^{1}$ project is to investigate the cerebral and cortical architecture underlying the visual recognition of complex stimuli, such as faces, objects and words. Much of the patient literature on visual recognition is based on single case studies. Patients are selected according to their symptom profiles and in-depth investigations are carried out. There are, however, some core limitations related to single case studies. Single cases in the literature represent a very selective and non-representative sample of patients, which limits the extent to which results can be generalised (Shallice \& Buiatti, 2011). Also, patients in different studies are assessed with different tests and experiments, thereby limiting the extent to which results can be compared across patients. To acquire novel insights into the field, the BoB-project adopts a different approach. A large group of patients was recruited according to their lesion location (within the regions supplied by the Posterior Cerebral Artery) rather than their symptomatology, and all patients were assessed with the same battery of sensitive tests of visual perception, making direct comparisons across participants possible. This method not only allows the identification of dissociations between deficits in face, word and object recognition, but also allows investigations of systematic associations between deficits in different visual categories (Starrfelt \& Robotham, 2018). A control group that is closely matched for age and education at the group level was also recruited and assessed. Structural and functional imaging data were also collected. The first behavioural results from the BoB-project are published in (Rice et al., CORTEX-D-20-00662R2). Here, we present in detail the extensive test battery that was developed for the Back of the Brain project assessing low-level, intermediate and high-level visual perception.

\section{Method}

\subsection{Designing the behavioural test battery}

The BoB behavioural test battery was designed to test the range and specificity of visual perceptual deficits following stroke. The test battery had the following constraints determined by the project protocol and budget:

A. Maximum 9 hours completion time for a typical patient with brain injury.

B. Assessment of each patient spread over maximum three sessions distributed over maximum three days.

\footnotetext{
${ }^{1}$ BoB: Back of the Brain project
} 
Creating the test battery involved the following steps:

Step 1: Identify lower-level, intermediate and higher-level visual perceptual functions as well associated functions that are relevant for the study

A literature search was carried out to identify functions that could be relevant to assess, and additional functions added following discussions among the co-authors (summarised in Figure 1).

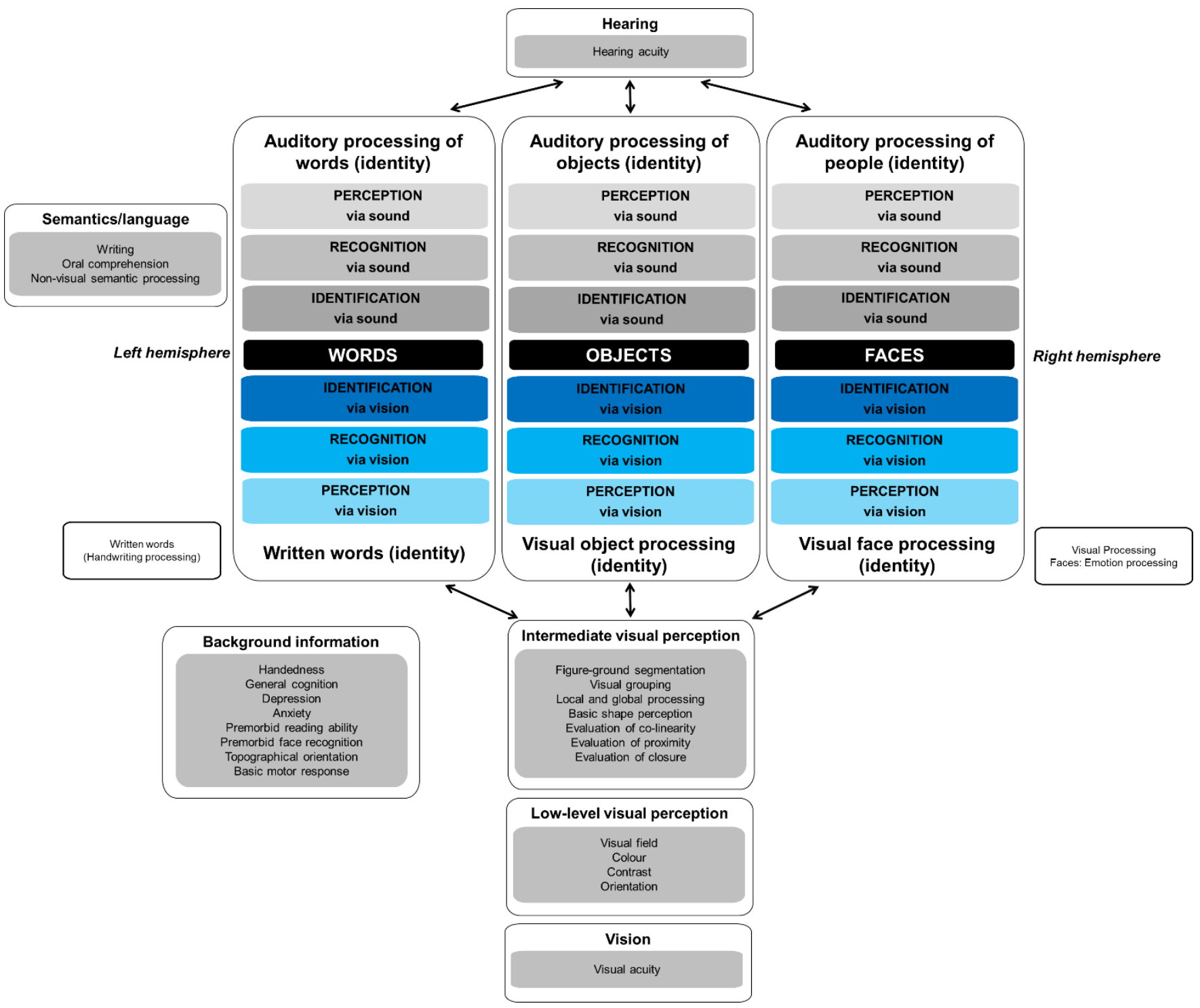

Figure 1: Functions that could be relevant to assess in the Back of the Brain project.

Step 2: Literature search to identify relevant tests and create a "dream scenario" test battery.

Tests that fulfilled as many of the following criteria as possible were prioritised:

A. Available in English

B. Short testing time to limit fatigue 
C. Validated and/or previously used in research

D. Central/vertical presentation of stimuli to limit the effects of visual field defects on performance

E. Tests assessing non-visual functions must be as visually simple as possible

This led to a "Dream scenario" test battery that was piloted in a group of patients with posterior stroke.

Step 3: Prioritize functions to create a "final version" of the test battery.

After piloting the "dream scenario", many tests/experiments were shortened or removed from the test battery to fit the time constraints of the project. Only those considered most important were included in the final test battery (Figure 2).

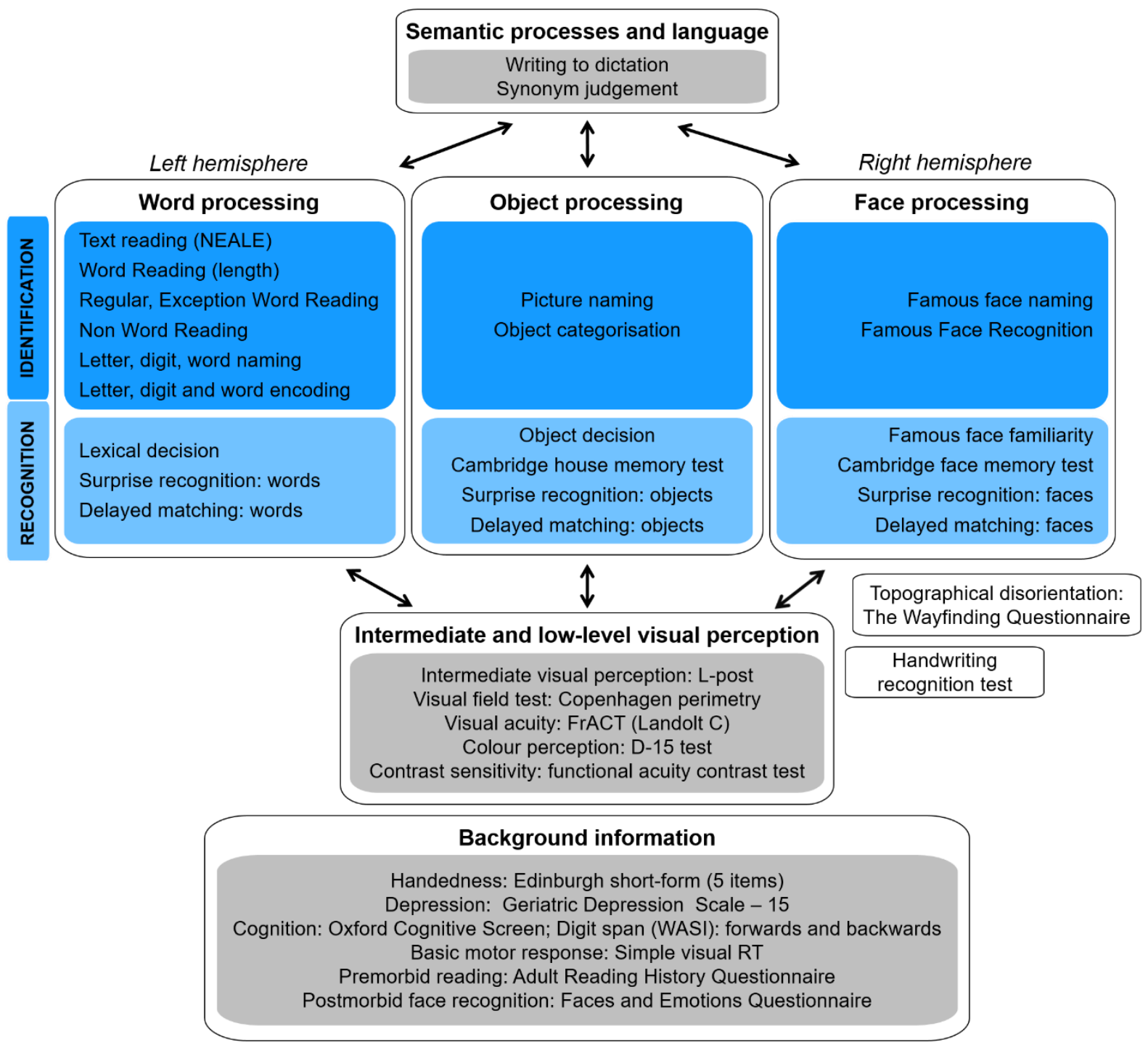

Figure 2: Back of the Brain behavioural test battery. 


\subsection{Key challenge related to designing the behavioural test battery}

In order to analyse possible dissociations and associations between face, object and word recognition, the behavioural test battery had to include tests of face, word and object recognition that were directly comparable. Ideally, to allow direct comparison across domains, included in the test battery should have:

A. Similar task demands

B. Measure the same level of processing (perception, recognition, and identification) (for a description of levels of processing see Robotham \& Starrfelt, 2018)

Many studies in the literature compare face and word processing, but none have to our knowledge succeeded in fulfilling both criteria. Three strategies are commonly used in the literature in order to compare face and word (and sometimes object-) recognition:

- Compare performance on typical tests of face processing to performance on typical tests of word processing (e.g., the Cambridge Face Memory Test (CFMT; Duchaine \& Nakyama, 2006) and Single word reading out loud). The problem with this strategy is that commonly used reading tests typically rely on overt naming, whereas the level of processing in typically used face recognition tests varies more (e.g., perception or memory).

- Test the stimulus categories in the same experimental setup to ensure similar task demands (e.g. delayed matching task). Using the same experimental set-up, does however not ensure that the same level of processing is being assessed. The semantic system or naming processes may be more involved in word and object conditions, but not when encoding unfamiliar faces.

- Compare typical effects found in normal participants or clinical groups with the different categories of stimuli (e.g., the face inversion effect and the word length effect). Tasks used to assess face inversion effect and the word length effect are, however, radically different, and the effects may not reflect processing at similar levels, thereby making direct comparisons problematic.

We conclude that differences in characteristics (mainly visual and semantic) between faces and words as visual entities make the problem of designing comparable tests seemingly impossible. This has been referred to as the "insoluble conundrum" (Robotham \& Starrfelt, 2017). The "Delayed matching and surprise recognition test for Words Objects and Faces" (WOF test) was designed in an attempt to overcome these challenges and enable comparison of performance with words, faces, and objects within the same experimental paradigms. In addition, to provide an alternative way of comparing recognition abilities across domains, a Lexical decision test (word or non-word), an Object decision test (object or non-object) and a Face familiarity test (famous or non-famous face) were 
included. Naming tests were also included (Word reading - length, Picture Naming and Famous Face Naming) to enable comparisons across domains at the identification level (see section 2.3.3. for details about the tests).

\subsection{BoB test battery}

Tests are categorised into background tests, tests of lower-level vision, and tests of higher-level vision.

\subsubsection{Background information}

\subsubsection{Edinburgh Handedness Inventory - Short Form}

Reason for inclusion: A questionnaire related to handedness was included as some of the core hypotheses of the BoB-project are related to cerebral lateralisation, which is known to be linked to handedness.

About the test: The Edinburgh Handedness inventory (Oldfield, 1971) is the most commonly used handedness questionnaire. The original questionnaire includes 10 items. In the BoB-project a shorter 4 -item version was used. The 4-item version is developed based on confirmatory factor analysis that was shown to have good reliability, factor score determinacy, and has been shown to correlate with scores on the 10-item inventory (Veale, 2014).

\subsubsection{Geriatric Depression Scale - 15 (GDS-15)}

Reason for inclusion: A depression screening tool was included as depression is known to be common amongst stroke survivors and known to affect performance on cognitive tests (Hackett et al., 2005).

About the test: The Geriatric Depression Scale (GDS) is a self-report measure that was designed for depression screening in older adults (Yesavage et al., 1983). One of the main advantages of the tool is that questions are answered with simple yes/no options making it easier for participants with cognitive challenges to complete. The questionnaire originally included 30 items, but a shorter 15 item version, the GDS-15, has been shown to have similar test properties as the longer version (Yesavage \& Sheikh, 1986). As most subjects in the BoB-project are in the older age range, the GDS was chosen as a depression screening tool. The shorter version (GDS-15) was chosen to limit assessment time. 


\subsubsection{Oxford Cognitive Screen (OCS)}

Reason for inclusion: Stroke can lead to a wide range of cognitive deficits. Screening of cognitive deficits was carried out to determine whether participants have substantial cognitive deficits (in other domains than visual perception), in order to enable interpretation of poor performance on the experimental tasks included in BoB. Amongst others, memory, language, executive deficits, and neglect could potentially affect performance on many of the experiments.

About the test: The OCS is a cognitive screening tool specifically designed for stroke patients (Demeyere et al., 2015). It covers the main cognitive domains that are commonly affected by stroke: Language, Attention, Memory, Praxis, and Number processing. The sub-tests of the OCS are: Picture naming; Semantics/picture pointing; Orientation; Visual field; Sentence reading; Number processing (writing and mental arithmetic); Broken hearts (neglect); Meaningless gesture imitation (praxis); Memory (recall \& recognition); Trail tasks (executive functions). Typically, the performance profile is the main source of information about OCS-results, but an index of cognitive impairment can also be derived by counting the number of impaired subtests. Published norms were used (Demeyere et al., 2015).

\subsubsection{Digit span: forwards and backwards}

Reason for inclusion: As working memory is not assessed in the Oxford Cognitive Screen, a measure of forwards and backwards digit span was included in the test battery. Many of the experiments included in the BoB put substantial demands on working memory. Few patients in the project were expected to have aphasic deficits, so verbal assessment of working memory was considered appropriate.

About the test: Digit span (forwards and backwards) from the Wechsler Adult Intelligence Scale IV (Wechsler, 2010) was chosen as it enables fast and efficient assessment of working memory and has detailed normative data available.

\subsubsection{Basic motor response}

Reason for inclusion: Stroke can lead to general cognitive slowing. A basic visual task was included to provide a baseline lower level visual reaction time measurement that can enable interpretation of reaction time data acquired in more complex experimental tests.

About the test: This experimental task was specifically designed to measure basic reaction times in the BoB-project. Many of the reaction time tasks included in BoB-project are 2AFC tasks, therefore a 
simple visual 2AFC task was designed in which participants must determine whether a stimulus, a narrow black rectangle that extends from one side of the screen to the other, is presented at the top or bottom of the screen (on a light grey background, see figure 3). The stimulus was chosen to ensure that patients with hemianopia and various forms for agnosia could complete the task. The test includes 4 practice trials and 20 test trials. The dependent measure was accuracy and correct reaction times.

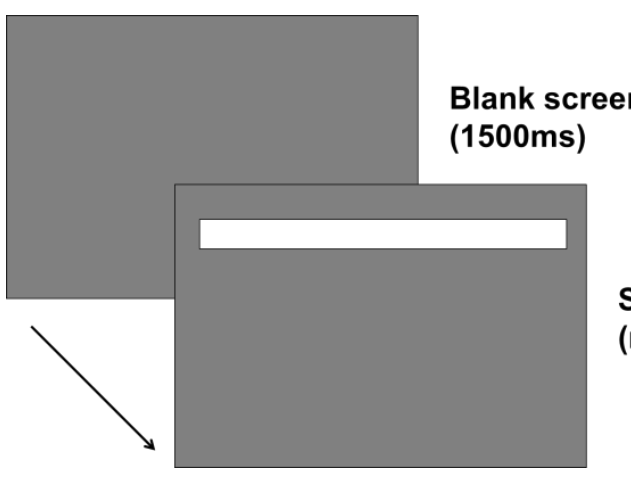

Stimulus display + response: up/down

(max: 1500ms)

Figure 3: Trial outline for the basic motor response test

\subsubsection{Adult Reading History Questionnaire}

Reason for inclusion: Some of the more specific questions of the BoB-project involve relations between pre-stroke reading experience/proficiency and severity of post-stroke alexia and prosopagnosia. Therefore, an assessment tool for reading abilities prior to stroke was included. In addition, identification of patients with dyslexic reading is important when interpreting data from reading tests.

About the test: The Adult Reading Questionnaire (Lefly \& Pennington, 2000) is designed to retrospectively assess developmental reading problems. It includes questions about experience with reading during childhood and reading ability in adulthood.

\subsubsection{Face recognition questionnaire}

Reason for inclusion: A face questionnaire was included to enable identification of patients with prosopagnosia. Indeed, one of the common core criteria used to diagnose prosopagnosia is that a patient has "complaints of impaired face recognition in daily life". Another reason for including a face recognition questionnaire was to enable the analysis of correlation between self-reporting of face recognition difficulties and performance on face processing tasks.

About the test: The Faces and Emotions questionnaire (Freeman et al., 2015) is designed to evaluate self-reported face recognition deficits following stroke. Questions were adjusted to be appropriate 
for people with acquired brain injury, and patients were asked to report their experiences following their stroke. Response options follow a scale from 1 (Definitely agree) to 4 (Definitely disagree), participants responded out-loud and their response was noted by the experimenter. The following 10 questions were selected from the Face Identity Recognition part of the questionnaire:

- I can usually remember what someone's face looks like, even if I've only met them once.

- I find it difficult to decide whether I know a face or not.

- I have trouble finding my friends in a crowded room.

- I occasionally fail to recognise myself in old photos.

- I often have conversations with people who appear to know me, but (at least initially) I have no idea who they were.

- I often rely on distinctive bodily features, hair, or clothing to help identify people.

- I rarely confuse characters in TV programs.

- I usually recognise my friends in old photographs.

- If I saw my neighbour at the shops, I would recognise them.

- If a friend changed their hairstyle I would most likely be able to identify them.

To ensure that potential problems were indeed related to brain injury, two additional questions were added:

- My ability to recognise faces has got worse since my stroke/head injury (Same scale as questions above)

- Is there anything else you want to tell me about your ability to recognise faces before your stroke/head injury? (Open question)

\subsubsection{Wayfinding Questionnaire}

Reason for inclusion: Wayfinding problems and topographic agnosia / amnesia have been reported following posterior cerebral artery stroke, and the literature suggests that many patients with acquired prosopagnosia also have wayfinding problems. While this function was not experimentally tested in the BoB-battery, questions about wayfinding abilities were included.

\section{About the test:}

The Wayfinding Questionnaire is designed to identify wayfinding problems (topographical orientation) after stroke (Claessen et al., 2016). The participants are asked to provide responses 
related to their current post-stroke abilities. Response options follow a Likert scale from 1 (Not at all applicable to me) to 7 (fully applicable to me). The following four questions from the original Wayfinding Questionnaire were included in the final protocol:

- I am good at understanding and following route descriptions.

- I can always orient myself quickly and correctly when I am in an unknown environment.

- I can easily find the shortest route to a known destination.

- I can usually recall a new route after I have walked it once.

The following two questions were also included:

- Since my stroke/head injury it is more difficult for me to find my way and orientate myself (also Likert scale)

- Is there anything else you want to tell me about your navigation and way finding abilities before your stroke? (Open question)

\subsubsection{Low-level and intermediate visual perception}

\subsubsection{Computerised Visual Field Test}

Reason for inclusion: A visual field test was included in the BoB-protocol as visual field defects are common following posterior cerebral artery stroke and can impact performance on many visual perceptual tasks.

About the test: The computerized Visual Field Screening Test (c-VFT) is a freely available screening tool (running in PsychoPy) that was developed at the Department of Psychology at University of Copenhagen (Nordfang et al., 2019). Commonly used perimetry tests are time consuming and can be difficult to run on patients with mobility limitations. The c-VFT can be run on a desktop or laptop computer and can therefore be carried out at bedside and only takes approximately five minutes to administer. The test probes 48 points within a radius of 10 degrees of visual angle (dva) around a central fixation cross. The points are equally sized dark circles presented against a light grey background. The stimuli probe at 1, 2, 5, and 10 degrees of visual angle. The test includes assessment of points along the horizontal and vertical meridians. Integrity of visual field along the horizontal meridian is particularly relevant for reading. The c-VFT has been validated against the Esterman test and the Humphrey Visual Field Analyzer (HFA), central 10-2 that are perimetry tests commonly used in clinical settings (Nordfang et al., 2019). 


\subsubsection{Freiburg Visual Acuity Test And Contrast Test (FrACT; Version 3.9.): Landolt C Acuity Test}

Reason for inclusion: The FrACT test was included to evaluate the status of participants' visual acuity when using their visual aids (glasses/lenses). Stroke patients are often in the older age range and many are expected to have acuity problems. Low visual acuity can affect performance on many visual tasks.

About the test: The FrACT Landolt C visual acuity test was chosen for the BoB-project as, in contrast to Log MAR charts in which all stimuli are presented simultaneously on a chart, stimuli are presented one at a time in the centre of the screen. This is useful for patients with visual field deficits or who are visually disorientated. Another advantage of FrACT is that Landolt Cs are used as stimuli rather than letters. The test is therefore better suited for patients with some forms of reading deficits than tests using letters from the alphabet. The FrACT presents Landolt Cs one at a time on a computer screen with varying sizes to assess visual acuity. It uses an adaptive staircase procedure to measure acuity threshold (Bach, 1996). For more information about the test: https://michaelbach.de/fract.

\subsubsection{Functional acuity contrast test (FACT)}

Reason for inclusion: A contrast sensitivity test was included in the protocol. It has been hypothesised that the visual processing of faces and words could rely differentially on low or high spatial frequency information, and that such differences may explain why patients are more impaired in one category than the other. The test has previously been used in a large-scale study of left posterior brain injury (Roberts et al., 2013).

About the test: The functional acuity contrast test (FACT; http://www.stereooptical.com/) is a diagnostic tool that evaluates sensitivity across a range of spatial frequencies and contrast $s$ (Ginsburg, 1984). . The test chart comprises a progression of high-quality, sine-wave gratings that probe sensitivity to $1.5,3,6,12$, and 18 cycles per degree. The contrast step between each grating patch is $0.15 \log$ units. The contrast range spans the variation of contrast sensitivity found in the normal population. Following the standard instructions, participant were asked to decide whether each grating was tilted right, or left. Normative limits which include $90 \%$ of the normal population are used to help minimize the potential for false positives. This test was performed with both eyes open, rather than for each eye individually. 


\subsubsection{The Farnsworth D-15 test of colour perception}

Reason for inclusion: The Farnsworth D-15 test of colour perception (Linksz, 1966) was included to identify congenital colour blindness as well as acquired achromatopsia. Achromatopsia may arise following PCA strokes, and it is possible that a deficit in colour perception affects the ability to recognise some types of complex stimuli more than others. E.g., it has been shown that achromatopsia can co-occur with prosopagnosia, however, little is known about the relationship between the two deficits (Bouvier \& Engel, 2006).

About the test: The D-15 is a modification of the Farnsworth-Munsell 100 Hue test (Farnsworth, 1943). The 15 cap version is intended for screening purposes (Linksz, 1966). The test contains 15 caps with different colours. The "pilot" cap is fixed to the left of the tray. The other caps are presented to the participant in mixed order. Participants are asked to "select the cap which is the closest possible match to the pilot cap". The chosen cap is placed to the right of the pilot cap. The participant must then "choose the closest colour match to the cap that was just chosen". This procedure is repeated until all caps have been placed in a row. Different result patterns indicate different forms of colour vision defects.

\subsubsection{Leuven Perceptual Organisation Screening test (L-POST, midlevel vision), modified}

Reason for inclusion: The L-POST was included to measure mid-level perceptual processing, e g., segmentation and grouping. Difficulties in processing complex visual stimuli can in some cases be caused by deficits in mid-level visual perceptual processing. By assessing this level of visual perception, investigation of whether (some types of) mid-level perceptual deficits affect or are related to processing of some visual categories more than others is made possible.

About the test: The L-POST is a computerized screening tool designed to assess deficits in mid-level vision (Torfs et al., 2014; Vancleef et al., 2015). It includes 15 subtests assessing a wide range of midlevel processes, such as figure-ground segmentation, local and global processing, shape perception, and the ability to use a variety of grouping cues e.g., proximity, and closure. It is an internet based tool, designed for use in both clinical and research settings. In the original version, performance is determined on the basis of accuracy alone. For the BoB-project, a modified version of the test was created in OpenSesame to enable both accuracy and reaction time measurements. The following sub-tests were included in the BoB-protocol: Fine shape discrimination; Shape ratio discrimination (Efron); RFP contour integration; Figure-ground segmentation; Embedded figure detection; RFP texture segmentation; Kinetic object segmentation; Dot counting; Global motion detection. In the sub-tests that use static images, the overall set-up is similar to the original version of the L-POST. 
Participants are presented with a target image at the top of the screen and three test images below. Participants must determine as fast as possible which of the test images are most similar to the target image. They can respond as soon as the stimuli appeared on the screen, and in contrast to the original version of the L-POST in which response time is unlimited, participants in the OpenSesame version of the L-POST have a maximum of 10 seconds to provide a response. The video subtests of the OpenSesame version of the L-POST differ from the original due to technical reasons. A target video and 3 response images (for the Kinetic object segmentation and Dot counting subtests) or 3 response videos (for the Global motion detection subtest) are played for 5 seconds, after which the target video disappears and only the response images are shown (for the global motion detection subtest, response videos are replaced by still pictures from the response videos). Participants can only respond after the videos have disappeared and have a maximum of 10 seconds to respond. This stands in contrast to the original version of the L-POST in which participants are required to provide a response while the video is running on the screen.

\subsubsection{High-level visual processing}

\subsubsection{Delayed Matching and Surprise Recognition test of Words, Objects and Faces (WOF test)}

Reason for inclusion: This test was included in order to compare recognition abilities across the categories of faces, words and objects. The experiment uses the same paradigm to assess face, word and object recognition, leading to easier comparison across categories.

About the test: The Delayed Matching Test and Surprise Recognition Test was developed specifically for the BoB-project and involves two parts: a delayed matching test and a surprise recognition test (Robotham, 2019). The Delayed Matching Test assesses the ability to build a short-term representation of a stimulus and then match it with the same or a novel stimulus. The Surprise Recognition test that is administered directly after is an old/new recognition paradigm that assesses whether participants can recognise stimuli that were used in the Delayed Matching part of the test. They are not told that there will be a subsequent recognition test when performing the Delayed matching part. Processing of words, objects and faces are assessed independently in each part. With its two separate parts, a distinction can be made between recognition problems that are caused by a deficit in storing a representation over longer time from deficits related to problems in creating a short-term representation of a stimulus and matching it with a currently viewed stimulus.

Delayed Matching Test 
Materials: For each category, four groups of three visually similar stimuli are used (12 uncropped faces, 12 words, and 12 objects; Figure 4). All images are in black and white. The faces were selected from the Radboud Faces Database (Langner et al., 2010). All faces are presented in frontal view with neutral emotional expressions. Two clusters of three male faces and two clusters of three female faces are used. The three faces in a cluster have similar hairstyles and similar visual features (see Figure 4). For the word stimuli, four clusters of three 4-letter words are used. Words in the same group only differ by one letter. In group 1, the first letter changes, in group 2, the second letter changes; in group 3, the third letter changes; and in group 4, the fourth letter changes. The task can therefore not be performed by focusing on a single letter position. Words are presented in lowercase writing in Arial font. The object stimuli includes four clusters of images representing four different object categories: cars, butterflies, boots, and flowers.

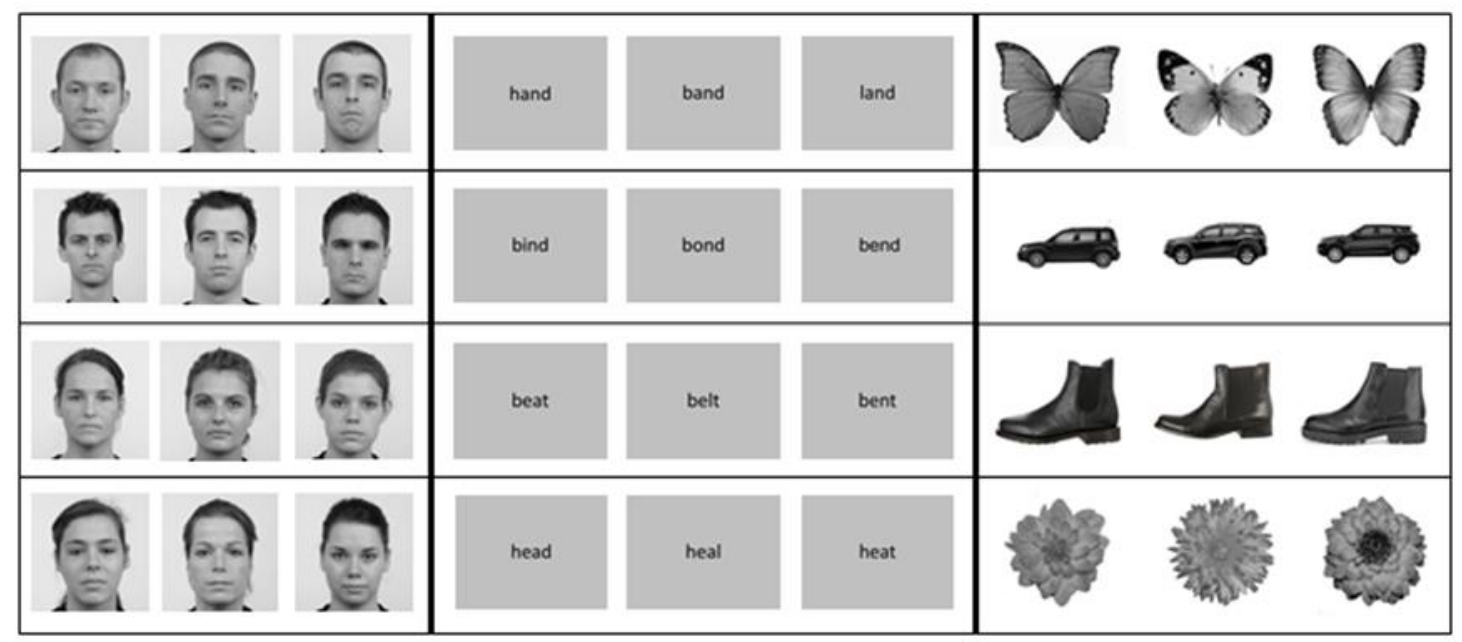

Figure 4. Stimuli - Delayed matching test

Procedure: The three categories are assessed in separate blocks in the following order: faces, words and objects. A practice session with four practice trials precedes each block. One trial consists of a target stimulus followed by a test stimulus (Figure 5 ). In $50 \%$ of trials, the test stimulus is the same as the target stimulus, and in $50 \%$ of trials, the test stimulus is a different stimulus (coming from the same cluster). Participants must determine via button-press whether the test and target stimuli is the same or different. Accuracy and reaction times are recorded. To avoid the task being a change detection task, test images are presented in smaller dimensions (2/3) than the target images in $50 \%$ of trials and in larger dimensions (4/3) than the target images in $50 \%$ of trials. Each block (category) 
involves 48 trials and each cluster of three stimuli is assessed through 12 trials. Trials are presented randomly within a block.

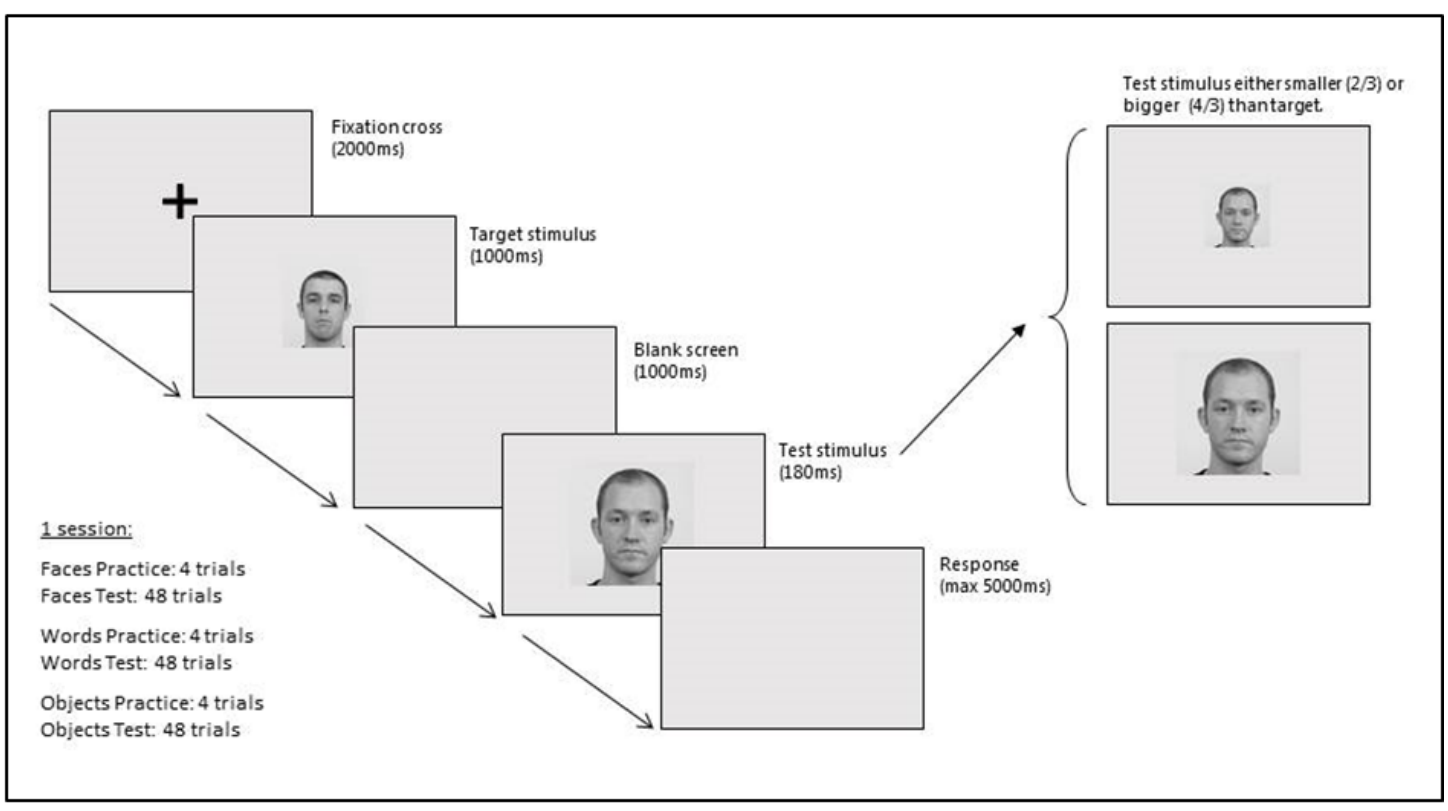

Figure 5: Trial outline for Delayed matching test

\section{Surprise Recognition Test}

Materials: The 36 stimuli used in the Delayed Matching part of the test are re-used in this part of the test (Figure 4), 12 novel faces, 12 novel words, and 12 novel objects are also included (Figure 6). The novel stimuli were selected so that they pairwise closely matched the stimuli used in the Delayed Matching part of the test. Each new face was selected to look highly similar to a face used in the Delayed Matching part of the test. Each new word differed from the words previously used with one letter only. Each new object was selected to look highly similar to one of the objects previously used. Similarity between images was not formally controlled. 


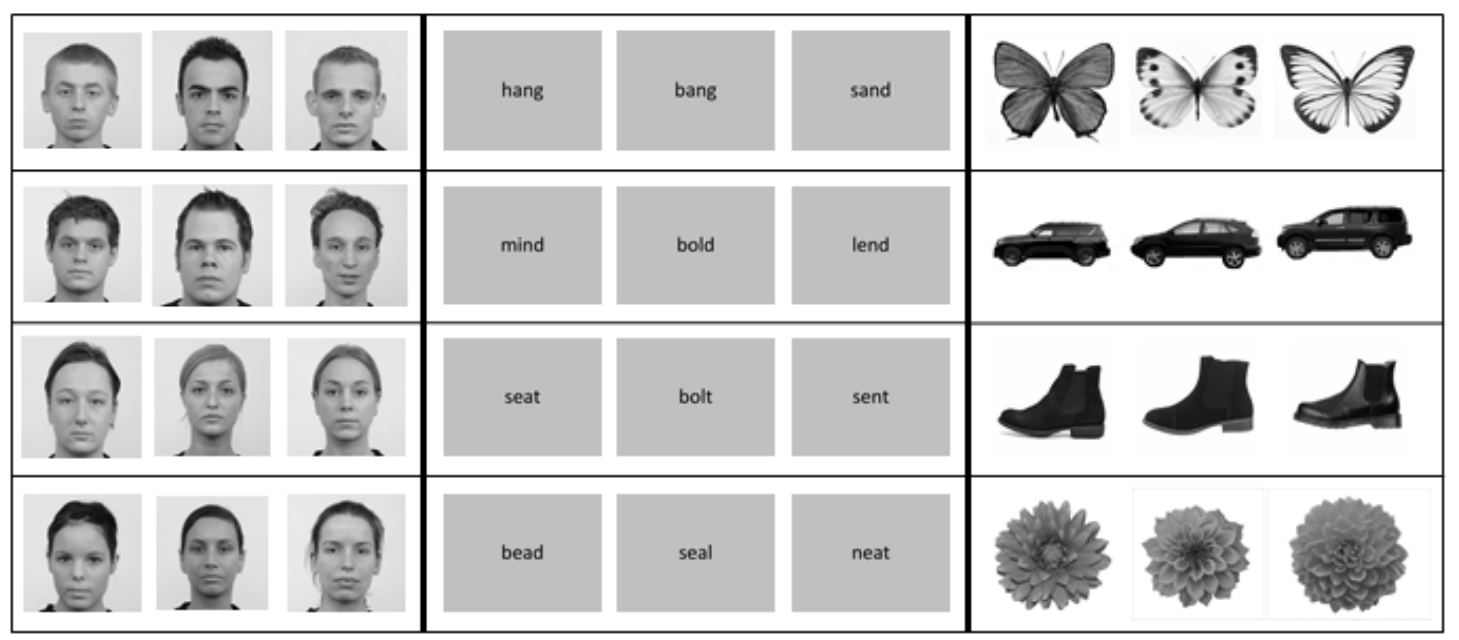

Figure 6. Stimuli - Novel distractors for Surprise recognition test

Procedure: The Surprise Recognition paradigm is run following a short break after the Delayed Matching paradigm. Categories are again presented in separate blocks and are presented in the same order as in the Delayed Matching paradigm: faces, words and objects. One trial consisted of a novel face and a target face being presented vertically on a screen. In $50 \%$ of trials the target is on top and $50 \%$ of trials the target is at the bottom of the screen. Participants are asked to determine which of the images they have seen before by pressing the $\uparrow$ key or the $\downarrow$ key. A trial ends when the participant presses a response key (Figure 7). Accuracy and reaction times are recorded. Each target face is presented once. There are therefore 12 trials in each block.
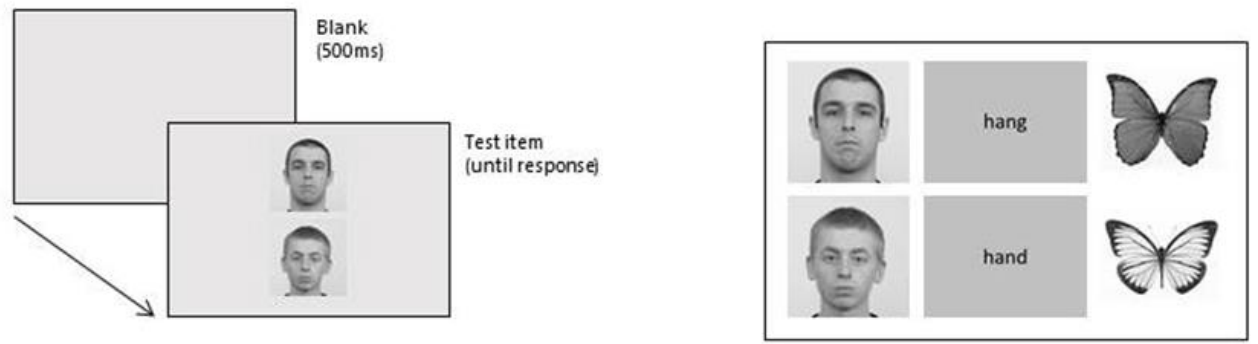

1 session:

Faces Test: 12 trials

Words Test: 12 trials

Objects Test: 12 trials

Figure 7: Trial outline for the Surprise recognition test 


\subsubsection{Lexical Decision / Object Decision / Face Familiarity Decision}

Reason for inclusion: A task that involves determining whether an item is familiar (deciding whether one has seen a given stimulus before or not) was included for each category of interest: words (lexical decision: word or non-word), objects (object decision: object or non-object), and faces (face familiarity: famous or non-famous face). This enables the comparison of visual recognition abilities across categories, without the need for a verbal (naming) output. The lexical decision test involves deciding whether a letter-string stimulus is a word or a non-word, and is commonly used to assess reading abilities in acquired reading disorders (Behrmann et al., 1998; Behrmann \& Plaut, 2014). Lexical decisions may be performed based on pre-semantic, visual lexical representations. The Object Decision test involves determining whether an image is depicting an object or a non-object. The nonobjects in the current project were chimeric nonobjects created from parts of real objects, and the test is considered to primarily reflect pre-semantic processing (visual long term memory; Gerlach, 2009). The Famous Face Familiarity Decision test assesses the ability to recognise a face as familiar. Participants must match the perceived face to a representation stored in long term memory. Participants are shown one face at a time and must determine if it is a famous face or a novel face. This task is a measure of both perceptual and semantic processing.

Lexical decision - About the test: A 60-item lexical decision task was administered to assess word recognition. Participants were presented with one stimulus at a time centrally on the screen and had to indicate via button-press as quickly and accurately as possible whether the letter-string was a word or not. Items were either 3, 5, or 7 letters in length. Non-words were phonologically plausible letter combinations. The main dependent variables were accuracy and correct response time. Stimuli were selected from the task used by (Behrmann \& Plaut, 2014), and included half the stimuli from the original test. See supplementary material for list of words included in the task.

Object decision - About the test: The 72-item test that was included in the BoB-protocol has been described in many publications (Gerlach, 2009; Starrfelt et al., 2010). The stimuli were presented one at a time centrally on a screen and participants were required to respond, via button-press, as quickly and accurately as possible whether the stimulus depicted a real object or a (chimeric) nonobject. The main dependent variables were accuracy and correct response time.

Face familiarity decision - About the test: This test contained 80 items, including the 40 famous faces included in the Famous Face Naming task. Faces were presented one at a time centrally on a screen and participants had to determine as quickly and accurately as possible via button-press whether the face was famous or not. The dependent measures were accuracy and correct response time. The test was designed specifically for the Back of the Brain project. 


\subsubsection{Cambridge Face Memory Test (CFMT)}

Reason for inclusion: The CFMT was included as it is the most widely used test for assessing face recognition abilities. This test is highly sensitive to face recognition problems in prosopagnosia. About the test: During the test, participants learn a set of 6 new male faces, and then have to recognise them amongst two distractors, either in the presence of visual noise or without (Duchaine \& Nakayama, 2006). The dependent measure for this test is accuracy.

\subsubsection{Cambridge House Memory Test (CHMT)}

Reason for inclusion: The CHMT was included as a non-face control task for the CFMT. The test assesses house recognition abilities and enables evaluation of the specificity of a participant's face recognition deficits.

About the test: The test has the same experimental set-up as the CFMT but involves learning a set of 6 new houses and then recognising them amongst distractors, either in the presence of visual noise or without (Martinaud et al., 2012). The dependent measure for this test is accuracy.

\subsubsection{Word reading (length)}

Reason for inclusion: This test measures response time and accuracy when reading words of different lengths and enables calculation of the word length effect, which is a core characteristic of pure alexia. Subjects with hemianopia typically also show a word length effect (although more modest).

About the test: The test has been used in previous investigations of pure alexia (Habekost et al., 2014; Starrfelt et al., 2009). Participants were asked to read 75 regularly spelled single words outloud as quickly and accurately as possible. Items were either 3, 5, or 7 letters in length (25 words per length). Each item was displayed on the screen until a response was recorded or a maximum of 4 seconds. Correct response times from stimulus onset to vocal response were measured using a voice key. Accuracy was recorded by the experimenter and responses were recorded using a Dictaphone for the purposes of error analysis. Responses provided after more than four seconds were counted as errors. See supplementary material for list of words included in the test.

\subsubsection{Word reading: regular, exception, non-word reading}

Reason for inclusion: The test measures response time and accuracy when reading non-words, exception words and regular words (Graham et al., 2000; Patterson \& Hodges, 1992). The test was 
included to enable more detailed characterisation of reading deficits in participants with posterior cerebral artery stroke.

About the test: This test included 84 items ( 42 regular words, 42 exception words, 20 non-words). Participants were presented with words one at a time on the screen and were instructed to read each word out loud as quickly and as accurately as possible. The voice key procedure was the same as that described for the word reading (length) test above. Items were presented on the screen until a response was made or for a maximum of 4 seconds. Accuracy was also recorded by the experimenter. See supplementary material for full list of stimuli included in the test.

\subsubsection{Naming single letters, digits and 3-letter words}

Reason for inclusion: The reasons for inclusion were twofold: to evaluate participants' letter/digit/word naming abilities and to familiarise the participants with the stimuli for the psychophysical single item report experiment.

About the test: This test is a modified version of experiment 2a in (Habekost et al., 2014), which includes single letters and words. A digit condition was added for the BoB-protocol to enable analysis of the relationship between letter and digit recognition. Participants were asked to name 30 single letters, 30 single digits, and 30 three-letter words in different blocks. Reaction times (voicekey) and accuracy were measured. See supplementary material for list of stimuli included in the test.

\subsubsection{Single item report (digits, letters, and words)}

Reason for inclusion: This experiment measures the visual component of letter, word, and digit recognition without being affected by motor components of the response. The test was included to compare performance to the naming task described above and can be used to determine whether there is a deficit in visual recognition or naming.

About the test: This test is a modified version of experiment 2b in (Habekost et al., 2014), which includes single letters and words, and measures the word superiority effect. A digit condition was added for the BoB-protocol to enable analysis of the relationship between letter and digit recognition. The test is a brief version of a psychophysical experiment presenting stimuli (letters, words and digits in separate blocks) at varying, short exposure durations $(20,30,50,80$ and 100 msec, 10 trials per exposure duration per stimulus type). The dependent measure is overall accuracy across exposure durations, which can be compared between stimulus types. In addition, TVA-based analyses can be carried out on these data, allowing for estimation of perceptual threshold and 
processing speed for digits, letters, and words respectively (see experiment 2 in Starrfelt et al., 2013, for analyses of similar data).

\subsubsection{Text reading (NEALE)}

Reason for inclusion: The Neale Analysis of Reading Ability (Neale, 1999) measures accuracy, comprehension and rate of reading. It is a standardised test designed to measure reading progression in children and it produces a measure of words read per minute and participants' ability to comprehend what they are reading. The test was previously used in a study involving participants with central alexia (Woodhead et al., 2018). Level one and two texts from the test were included in the BoB-protocol to obtain a measure of word and sentence reading comprehension.

About the test: Participants are asked to read two passages of 26 words and 56 words, followed by four and eight comprehension questions, respectively. For the BoB project, Participants' responses were recorded using a Dictaphone for transcription of errors and calculation of reading speed.

\subsubsection{Picture Naming}

Reason for inclusion: A picture naming test that has been used in previous studies (Roberts et al., 2013) was included in the protocol to enable comparison of identification abilities across categories. Picture naming abilities can be compared to famous face naming abilities and word reading abilities.

About the test: Participants are required to name 45 black and white line drawings of objects as quickly and accurately as possible. The stimuli consists of 30 living items (animals, insects) and 15 non-living items (musical instruments, vehicles, tools). Within the living items there is a manipulation of "homomorphy" (Tranel et al., 1997); the amount to which an items contour is shared with other exemplars within that category (15 living items had high homomorphy and 15 living items had low homomorphy). Previous studies have shown that posterior stroke patients may show category effects during naming, where performance is worse when naming living items compared to nonliving items. The manipulation of homomorphy is included to test the hypothesis that any such category effects are due to low-level perceptual effects caused by the high homomorphy overlap in living items compared to non-living items (which tend to be more unique in their contour). The same voice key procedure described for the word reading tests was adopted for the BoB project. Items were presented on the screen until a response was made or for a maximum of 6 seconds. Accuracy was recorded by the experimenter. 


\subsubsection{Object Categorisation}

Reason for inclusion: An Object Categorisation test was included to measure visual recognition and visual-semantic processing without requiring a verbal (naming) output and to measure category effects. The task requires participants to determine if an object is natural or manmade, and enables the analysis of category effects.

About the test: This test is a short version of the object categorisation tasks used by e.g. (Gerlach, 2009). Stimuli are 36 Snograss and Vanderwart line drawings: 18 representing natural objects and 18 representing man-made objects. Images were presented one at a time and participants were required to respond via button-press as quickly and accurately as possible whether it depicted a natural or a manmade object. The dependent variables were correct response time and accuracy. See supplementary material for full list of stimuli included in the test.

\subsubsection{Famous Face Naming}

Reason for inclusion: A Famous Face Naming test was included to enable comparison of identification abilities across categories. Famous Face Naming abilities can be compared to Picture Naming Abilities and Word Reading abilities.

About the test: This test was used in a previous case-series investigation of posterior cerebral lesions (Roberts et al., 2015). The test contains 40 items, pictures of famous faces are presented one at a time centrally on a screen and participants are asked to name the person out loud as quickly and as accurately as possible. If they are unable to provide their name, recognition of the person is tested (e.g., provision of why the person is famous, what they do, where they live etc.). The main measure for this test was accuracy, reaction time data was not scored due to the extensive verbal output. Responses were scored according to whether the correct name was provided and whether correct semantic information was provided. The items included in this test were also included in the Face Familiarity test (the two tests were administered on different days, the face familiarity test first).

\subsubsection{Associated functions}

\subsubsection{Writing to dictation}

Reason for inclusion: A writing to dictation test was included in the protocol to establish whether the participants with alexia have intact spelling. 
About the test: The original writing to dictation test includes 80 items (Graham et al., 2000) and to make the test shorter and harder, only the 40 low predictability words were included in the BoBprotocol (alongside 20 non-words). The experimenter reads each item aloud to the participant, who then has to repeat each word back, and then write the item down on a score sheet. The experimenter measures two reaction times: (1) planning time: measured as the time from correct repetition to the time writing began, (2) writing time: measured from the start of writing to the end. The main dependent variables were accuracy and the two measures of response time. See supplementary material for full list of stimuli included in the test.

\subsubsection{Surprise Handwriting Test}

Reason for inclusion: A Surprise Handwriting Recognition Test was included to assess whether participants can read something that they have written and whether they can recognise their own handwriting. Early case studies of Pure Alexia describe participants as unable to read something they have written a short time previously (Bub et al., 1993). Also, while reading is generally considered to be supported by processes that are left lateralised, some studies suggest that the recognition of handwriting style may be right lateralised and may occur together with face processing deficits (Hills et al., 2015). Assessing handwriting recognition enables investigation of the lateralisation of such deficits.

About the test: This test was devised for the purposes of the current study. On the first day of testing participants were asked to write a simple sentence taken from a level one passage in the Neale (Neale, 1999). Handwritten samples of the remaining sentences within this Neale passage were obtained prior to testing. The participants' writing was scanned into the computer and inserted as the second sentence within the Neale passage. The participants were presented with a level one passage from the Neale to read in four different handwritings, one of which was their own. Three measures were obtained; i) the time taken to read the passage, ii) whether the participant spontaneously recognised the handwriting as their own, and iii) whether the participant was able to identify the handwriting as their own upon forced choice.

\subsubsection{Synonym Judgement Task}

Reason for inclusion: The Synonym Judgement Task is one of the standard tests assessing semantic memory. The test can be used to explore even mild semantic problems (impaired accuracy on the hardest, lower frequency items). The test was included to determine whether a participant's recognition problem can be explained, at least partially, by semantic problems. 
About the test: The task has been used in many previous studies, including with other patient groups (Jefferies et al., 2009), and healthy participants (Binney et al., 2010). For each trial a written target word is presented on screen, alongside three choices. Participants are instructed to determine which of the choice items is associated with the target item. Stimulus presentation was adjusted for the BoB-project so words were presented vertically rather than horizontally. Stimuli were presented visually and as spoken words, to avoid biasing against patients who struggled to read. The experimenter read each word out loud and pointed to each word on the screen before prompting a response (for this reason reaction times were not collected on this task). Stimuli varied according to imageability (high vs. low) as well as frequency (high, medium, low). The task included 96 items. 


\subsection{Procedure}

Tests were either carried out using paper-and-pencil, Laptop computers with a screen resolution of 1366 x 768 (London: Dell latitude e6430 running on CORE i5 Windows 7 Professional; Manchester: Lenovo T560 running on Windows 7), or desktop computers with a screen resolution of $1920 x 1080$ (Windows 7 Enterprise, 64-bit operating system, 24 Inch BenQ XL2430T screen).

Order of administration of tests was the same for all participants (see table 1 for order of tests, administration details and how to access tests). Tests for which there is ample normative data available or that control participants were expected to perform at ceiling level (example visual field test) were not included in the protocol for control participants. The behavioural test battery was administered over two or three days for patients and one or two days for controls. Participants sat at a distance of $57 \mathrm{~cm}$ from screens, unless otherwise specified in table 1.

Table 1: Administration of tests and test availability

\begin{tabular}{|c|c|c|c|c|c|c|}
\hline Order & Test & Equipment & $\begin{array}{l}\text { Testing } \\
\text { conditions } \\
\end{array}$ & $\begin{array}{l}\text { Response type and } \\
\text { registration }\end{array}$ & Original reference & How to access test \\
\hline 1 & $\begin{array}{l}\text { Edinburgh short- } \\
\text { form } 5 \text { item }\end{array}$ & $\begin{array}{l}\text { Paper- } \\
\text { pencil }\end{array}$ & $\begin{array}{l}\text { Ceiling } \\
\text { lighting }\end{array}$ & $\begin{array}{l}\text { Response sheet in } \\
\text { screening form. }\end{array}$ & (Veale, 2014) & $\begin{array}{l}\text { In original publication: } \\
\text { https://doi.org/10.1080/1357650x.201 } \\
\underline{\underline{3.783045}}\end{array}$ \\
\hline $2^{\mathrm{a}}$ & $\begin{array}{l}\text { Geriatric } \\
\text { Depression Scale - } \\
15\end{array}$ & Laptop & $\begin{array}{l}\text { Ceiling } \\
\text { lighting }\end{array}$ & $\begin{array}{l}\text { Experimenter or patient } \\
\text { responds on keyboard. }\end{array}$ & $\begin{array}{l}\text { (Yesavage \& Sheikh, } \\
\text { 1986) }\end{array}$ & $\begin{array}{l}\text { In original publication: } \\
\text { https://doi.org/10.1300/J018v05n01 } 0 \\
\underline{9}\end{array}$ \\
\hline $3^{a}$ & $\begin{array}{l}\text { Oxford Cognitive } \\
\text { Screen }\end{array}$ & $\begin{array}{l}\text { Paper- } \\
\text { pencil }\end{array}$ & $\begin{array}{l}\text { Ceiling } \\
\text { lighting }\end{array}$ & $\begin{array}{l}\text { Testing booklet, response } \\
\text { booklet. }\end{array}$ & (Demeyere et al., 2015) & www.innovation.ox.ac.uk \\
\hline 4 & $\begin{array}{l}\text { Digit span } \\
\text { forwards, } \\
\text { backwards WAIS } \\
\text { IV. }\end{array}$ & $\begin{array}{l}\text { Paper- } \\
\text { pencil }\end{array}$ & $\begin{array}{l}\text { Ceiling } \\
\text { lighting }\end{array}$ & Response sheet. & (Wechsler, 2010) & www.pearson.com/uk/ \\
\hline 5 & $\begin{array}{l}\text { Basic motor } \\
\text { response }\end{array}$ & Laptop & $\begin{array}{l}\text { Ceiling } \\
\text { lighting }\end{array}$ & $\begin{array}{l}\text { Subject responds on SR } \\
\text { box. }\end{array}$ & (Robotham, 2019) & $\begin{array}{l}\text { Available from Ro J. Robotham: } \\
\text { jer@psy.ku.dk }\end{array}$ \\
\hline
\end{tabular}




\begin{tabular}{|c|c|c|c|c|c|c|}
\hline 6 & $\begin{array}{l}\text { Face recognition } \\
\text { questionnaire }\end{array}$ & Laptop & $\begin{array}{l}\text { Ceiling } \\
\text { lighting }\end{array}$ & $\begin{array}{l}\text { Response sheet. } \\
\text { Experimenter or patient } \\
\text { responds on keyboard. }\end{array}$ & (Freeman et al., 2015) & $\begin{array}{l}\text { Original test in original publication: } \\
\text { https://doi.org/10.6084/m9.figshare.15 } \\
\underline{\text { 01441.v1 }} \\
\text { Items selected for current project listed } \\
\text { in section 2.3.1.7. Version amended for } \\
\text { BoB-project available from: } \\
\text { Randi.Starrfelt@psy.ku.dk }\end{array}$ \\
\hline 7 & $\begin{array}{l}\text { Wayfinding } \\
\text { questionnaire }\end{array}$ & Laptop & $\begin{array}{l}\text { Ceiling } \\
\text { lighting }\end{array}$ & $\begin{array}{l}\text { Response sheet. } \\
\text { Experimenter or patient } \\
\text { responds on keyboard. }\end{array}$ & (Claessen et al., 2016) & $\begin{array}{l}\text { Original test in original publication: } \\
\text { https://doi.org/10.1093/arclin/acw044 } \\
\text { Items selected for current project listed } \\
\text { in section 2.3.1.8. Version amended for } \\
\text { BoB-project available from: } \\
\text { Randi.Starrfelt@psy.ku.dk }\end{array}$ \\
\hline 8 & $\begin{array}{l}\text { Delayed Matching } \\
\text { and Surprise } \\
\text { Recognition test } \\
\text { (WOF test) }\end{array}$ & Laptop & $\begin{array}{l}\text { Ceiling } \\
\text { lighting }\end{array}$ & $\begin{array}{l}\text { Subject responds on SR } \\
\text { box. }\end{array}$ & (Robotham, 2019) & $\begin{array}{l}\text { Available from Ro J. Robotham: } \\
\text { jer@psy.ku.dk }\end{array}$ \\
\hline 9 & $\begin{array}{l}\text { Adult reading } \\
\text { history } \\
\text { questionnaire }\end{array}$ & Laptop & $\begin{array}{l}\text { Ceiling } \\
\text { lighting }\end{array}$ & $\begin{array}{l}\text { Experimenter or patient } \\
\text { responds on keyboard. }\end{array}$ & $\begin{array}{l}\text { (Lefly \& Pennington, } \\
\text { 2000) }\end{array}$ & $\begin{array}{l}\text { Original test in original publication } \\
\text { Items selected for current project (and } \\
\text { amended for stroke patients) available } \\
\text { from Randi.Starrfelt@psy.ku.dk or } \\
\text { jer@psy.ku.dk (Ro J. Robotham) }\end{array}$ \\
\hline 10 & $\begin{array}{l}\text { Famous Face } \\
\text { Familiarity } \\
\text { decision }\end{array}$ & Laptop & $\begin{array}{l}\text { Ceiling } \\
\text { lighting }\end{array}$ & $\begin{array}{l}\text { Subject responds on SR } \\
\text { box }\end{array}$ & Designed for project & $\begin{array}{l}\text { Available from } \\
\text { Matt.Lambon-Ralph@mrc- } \\
\text { cbu.cam.ac.uk }\end{array}$ \\
\hline 11 & $\begin{array}{l}\text { Synonym } \\
\text { judgement task }\end{array}$ & Laptop & $\begin{array}{l}\text { Ceiling } \\
\text { lighting }\end{array}$ & $\begin{array}{l}\text { Dual visual/verbal } \\
\text { presentation. } \\
\text { Experimenter responds } \\
\text { using keyboard }\end{array}$ & (Jefferies et al., 2009) & $\begin{array}{l}\text { Available from } \\
\text { Matt.Lambon-Ralph@mrc- } \\
\underline{\text { cbu.cam.ac.uk }}\end{array}$ \\
\hline 12 & $\begin{array}{l}\text { Leuven Perceptual } \\
\text { Organisation } \\
\text { Screening test } \\
\text { (modified) }\end{array}$ & Laptop & $\begin{array}{l}\text { Ceiling } \\
\text { lighting }\end{array}$ & $\begin{array}{l}\text { Subject responds on } \\
\text { keyboard. }\end{array}$ & (Torfs et al., 2014) & $\begin{array}{l}\text { Original version: } \\
\text { http://www.gestaltrevision.be/tests/in } \\
\underline{\text { dex.php?language=en }}\end{array}$ \\
\hline
\end{tabular}




\begin{tabular}{|c|c|c|c|c|c|c|}
\hline & & & & & & $\begin{array}{l}\text { Modified version available from Randi } \\
\text { Starrfelt (Randi.Starrfelt@psy.ku.dk) or } \\
\text { jer@psy.ku.dk (Ro J. Robotham) }\end{array}$ \\
\hline 13 & $\begin{array}{l}\text { Writing to } \\
\text { dictation }\end{array}$ & Laptop & $\begin{array}{l}\text { Ceiling } \\
\text { lighting }\end{array}$ & $\begin{array}{l}\text { Response sheet. } \\
\text { Experimenter records RTs } \\
\text { on laptop. }\end{array}$ & (Graham et al., 2000) & $\begin{array}{l}\text { See supplementary file for list of Items } \\
\text { selected for current project }\end{array}$ \\
\hline 14 & $\begin{array}{l}\text { Cambridge Face } \\
\text { Memory Test }\end{array}$ & Laptop & $\begin{array}{l}\text { Ceiling } \\
\text { lighting }\end{array}$ & $\begin{array}{l}\text { Subject responds on } \\
\text { keyboard. }\end{array}$ & $\begin{array}{l}\text { (Duchaine \& Nakayama, } \\
\text { 2006) }\end{array}$ & $\begin{array}{l}\text { Contact authors of original publication } \\
\text { https://doi.org/10.1016/i.neuropsychol } \\
\text { ogia.2005.07.001 }\end{array}$ \\
\hline 15 & Object decision & Laptop & $\begin{array}{l}\text { Ceiling } \\
\text { lighting }\end{array}$ & $\begin{array}{l}\text { Subject responds on SR } \\
\text { box. }\end{array}$ & (Gerlach, 2009) & $\begin{array}{l}\text { Available from } \\
\text { Randi.Starrfelt@psy.ku.dk }\end{array}$ \\
\hline 16 & $\begin{array}{l}\text { Cambridge house } \\
\text { memory test }\end{array}$ & Laptop & $\begin{array}{l}\text { Ceiling } \\
\text { lighting }\end{array}$ & $\begin{array}{l}\text { Subject responds on } \\
\text { keyboard. }\end{array}$ & (Martinaud et al., 2012) & $\begin{array}{l}\text { Contact authors of original publication } \\
\text { https://doi.org/10.1371/journal.pone.0 } \\
\underline{030433}\end{array}$ \\
\hline 17 & Lexical decision & Laptop & $\begin{array}{l}\text { Ceiling } \\
\text { lighting }\end{array}$ & $\begin{array}{l}\text { Subject responds on SR } \\
\text { box }\end{array}$ & $\begin{array}{l}\text { (Behrmann \& Plaut, } \\
\text { 2014) }\end{array}$ & $\begin{array}{l}\text { Modified version available from Randi } \\
\text { Starrfelt: } \\
\text { Randi.Starrfelt@psy.ku.dk } \\
\text { See supplementary file for word list. }\end{array}$ \\
\hline 18 & $\begin{array}{l}\text { Computerised } \\
\text { Visual Field Test }\end{array}$ & Desktop & Low light & $\begin{array}{l}\text { Subject responds on } \\
\text { keyboard. } 60 \mathrm{~cm} \text { away } \\
\text { from screen. }\end{array}$ & (Nordfang et al., 2019) & $\begin{array}{l}\text { https://psy.ku.dk/ansatte/?pure=da\%2 } \\
\text { Fpublications\%2Fcvft(c39487b2-2ad1- } \\
\text { 4cb0-bf6d-73d79eb87a06).html }\end{array}$ \\
\hline $19^{a}$ & $\begin{array}{l}\text { Naming single } \\
\text { letters, digits and } \\
\text { 3-letter words }\end{array}$ & Desktop & Low light & $\begin{array}{l}\text { Record with dictaphone. } \\
\text { Voice-key. Response } \\
\text { Sheets. Experimenter } \\
\text { responds on SR box. }\end{array}$ & (Habekost et al., 2014) & $\begin{array}{l}\text { Available from } \\
\text { Randi.Starrfelt@psy.ku.dk } \\
\text { See supplementary file for word list. }\end{array}$ \\
\hline 20 & $\begin{array}{l}\text { Single item report: } \\
\text { letters, digits and } \\
\text { words }\end{array}$ & Desktop & Low light & $\begin{array}{l}\text { Experimenter responds } \\
\text { on keyboard. }\end{array}$ & (Habekost et al., 2014) & $\begin{array}{l}\text { Available from } \\
\text { Randi.Starrfelt@psy.ku.dk } \\
\text { See supplementary file for stimulus list. }\end{array}$ \\
\hline 21 & $\begin{array}{l}\text { FrACT - Visual } \\
\text { acuity }\end{array}$ & Desktop & Low light & $185 \mathrm{~cm}$ away from screen. & (Bach, 1996) & www.michaelbach.de/fract \\
\hline
\end{tabular}




\begin{tabular}{|c|c|c|c|c|c|c|}
\hline & & & & $\begin{array}{l}\text { Researcher responds on } \\
\text { keyboard. Note: Dec VA } \\
\text { and LogMAR. }\end{array}$ & & \\
\hline 22 & $\begin{array}{l}\text { FACT - Contrast } \\
\text { sensitivity }\end{array}$ & Desktop & $\begin{array}{l}\text { Ceiling } \\
\text { lighting }\end{array}$ & & (Ginsburg, 1984) & www.stereooptical.com/ \\
\hline 23 & $\begin{array}{l}\text { Word reading } \\
\text { (length: } 3,5,7 \\
\text { letter words) }\end{array}$ & Desktop & $\begin{array}{l}\text { Ceiling } \\
\text { lighting }\end{array}$ & $\begin{array}{l}\text { Record with dictaphone. } \\
\text { Voice-key. Experimenter } \\
\text { responds on response } \\
\text { box. }\end{array}$ & (Starrfelt et al., 2009) & $\begin{array}{l}\text { Available from } \\
\text { Randi.Starrfelt@psy.ku.dk }\end{array}$ \\
\hline 24 & Picture naming & Desktop & $\begin{array}{l}\text { Ceiling } \\
\text { lighting }\end{array}$ & $\begin{array}{l}\text { Record with dictaphone. } \\
\text { Experimenter responds } \\
\text { on response box. }\end{array}$ & (Roberts et al., 2013) & $\begin{array}{l}\text { Available from Matt.Lambon- } \\
\text { Ralph@mrc-cbu.cam.ac.uk }\end{array}$ \\
\hline 25 & $\begin{array}{l}\text { Famous face } \\
\text { naming }\end{array}$ & Desktop & $\begin{array}{l}\text { Ceiling } \\
\text { lighting }\end{array}$ & $\begin{array}{l}\text { Record with dictaphone. } \\
\text { Experimenter responds } \\
\text { on response box. }\end{array}$ & (Roberts et al., 2015) & $\begin{array}{l}\text { Available from Matt.Lambon- } \\
\text { Ralph@mrc-cbu.cam.ac.uk }\end{array}$ \\
\hline 26 & $\begin{array}{l}\text { Word reading: } \\
\text { regular, irregular } \\
\text { and non-words }\end{array}$ & Desktop & $\begin{array}{l}\text { Ceiling } \\
\text { lighting }\end{array}$ & $\begin{array}{l}\text { Record with dictaphone. } \\
\text { Voice-key. . Experimenter } \\
\text { responds on response } \\
\text { box. }\end{array}$ & $\begin{array}{l}\text { (Graham et al., 2000; } \\
\text { Patterson \& Hodges, } \\
\text { 1992) }\end{array}$ & $\begin{array}{l}\text { Available from } \\
\text { Randi.Starrfelt@psy.ku.dk } \\
\text { See supplementary file for word } \\
\text { selected for current project. }\end{array}$ \\
\hline 27 & $\begin{array}{l}\text { Farnsworth D-15 } \\
\text { test of colour } \\
\text { perception }\end{array}$ & D-15 box & $\begin{array}{l}\text { Ceiling } \\
\text { lighting }\end{array}$ & $\begin{array}{l}\text { If error on first attempt, } \\
\text { repeat test. }\end{array}$ & (Linksz, 1966) & Test copyrighted. Various retailers. \\
\hline 28 & $\begin{array}{l}\text { NEALE: text } \\
\text { reading }\end{array}$ & $\begin{array}{l}\text { Paper- } \\
\text { pencil }\end{array}$ & $\begin{array}{l}\text { Ceiling } \\
\text { lighting }\end{array}$ & $\begin{array}{l}\text { Handwriting stimuli. } \\
\text { Response sheet. } \\
\text { Stopwatch. Record with } \\
\text { dictaphone. NEALE } \\
\text { booklet. }\end{array}$ & (Neale, 1999) & Test copyrighted. Various retailers. \\
\hline 29 & $\begin{array}{l}\text { Surprise } \\
\text { Handwriting } \\
\text { recognition test }\end{array}$ & $\begin{array}{l}\text { Paper- } \\
\text { pencil }\end{array}$ & $\begin{array}{l}\text { Ceiling } \\
\text { lighting }\end{array}$ & $\begin{array}{l}\text { Example handwriting. } \\
\text { Record with dictaphone. } \\
\text { Note: time to read; } \\
\text { Spontaneous } \\
\text { recognition? Y/N; Forced } \\
\text { choice recognition? Y/N }\end{array}$ & $\begin{array}{l}\text { Created for current } \\
\text { project }\end{array}$ & $\begin{array}{l}\text { Available from } \\
\text { Randi.Starrfelt@psy.ku.dk }\end{array}$ \\
\hline
\end{tabular}




\begin{tabular}{|l|l|l|l|l|l|l|}
\hline 30 & $\begin{array}{l}\text { Object } \\
\text { categorisation }\end{array}$ & Laptop & $\begin{array}{l}\text { Ceiling } \\
\text { lighting }\end{array}$ & $\begin{array}{l}\text { Subject responds on SR } \\
\text { box. }\end{array}$ & (Gerlach, 2009) & $\begin{array}{l}\text { Available from } \\
\text { Randi.Starrfelt@psy.ku.dk } \\
\text { See supplementary file for list of object } \\
\text { drawings included in current study. }\end{array}$ \\
\hline
\end{tabular}

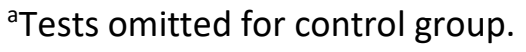




\section{References}

Bach, M. (1996). The Freiburg Visual Acuity test--automatic measurement of visual acuity. Optom Vis Sci, 73(1), 49-53.

Behrmann, M., \& Plaut, D. C. (2014). Bilateral Hemispheric Processing of Words and Faces: Evidence from Word Impairments in Prosopagnosia and Face Impairments in Pure Alexia. Cerebral Cortex, 24(4), 1102-1118. https://doi.org/10.1093/cercor/bhs390

Behrmann, M., Plaut, D. C., \& Nelson, J. (1998). A literature review and new data supporting an interactive account of letter-by-letter reading. Cogn Neuropsychol, 15(1/2), 7-51. https://doi.org/10.1080/026432998381212

Binney, R. J., Embleton, K. V, Jefferies, E., Parker, G. J. M., \& Ralph, M. A. L. (2010). The Ventral and Inferolateral Aspects of the Anterior Temporal Lobe Are Crucial in Semantic Memory : Evidence from a Novel Direct Comparison of Distortion-Corrected fMRI , rTMS, and Semantic Dementia. November. https://doi.org/10.1093/cercor/bhq019

Bouvier, S. E., \& Engel, S. A. (2006). Behavioral deficits and cortical damage loci in cerebral achromatopsia. Cerebral Cortex, 16(2), 183-191. https://doi.org/10.1093/cercor/bhi096

Bub, D. N., Arguin, M., \& Lecours, A. R. (1993). Dejerine, Jules and his interpretation of pure alexia. Brain and Language, 45(4), 531-559. https://doi.org/10.1006/brln.1993.1059

Claessen, M. H. G., Visser-Meily, J. M. A., de Rooij, N. K., Postma, A., \& van der Ham, I. J. M. (2016). The Wayfinding Questionnaire as a Self-report Screening Instrument for Navigation-related Complaints After Stroke: Internal Validity in Healthy Respondents and Chronic Mild Stroke Patients. Archives of Clinical Neuropsychology. https://doi.org/10.1093/arclin/acw044

Demeyere, N., Riddoch, M. J., Slavkova, E. D., Bickerton, W. L., \& Humphreys, G. W. (2015). The Oxford Cognitive Screen (OCS): validation of a stroke-specific short cognitive screening tool. Psychological Assessment, 27(3), 883-894. https://doi.org/10.1037/pas0000082

Duchaine, B. C., \& Nakayama, K. (2006). The Cambridge Face Memory Test: Results for neurologically intact individuals and an investigation of its validity using inverted face stimuli and prosopagnosic participants. Neuropsychologia, 44(4), 576-585. https://doi.org/http://dx.doi.org/10.1016/j.neuropsychologia.2005.07.001

Farnsworth, D. (1943). The Farnsworth-Munsell 100-Hue and Dichotomous Tests for Color Vision*. Journal of the Optical Society of America, 33(10), 568-578. https://doi.org/10.1364/JOSA.33.000568

Freeman, P., Palermo, R., \& Brock, J. (2015). Faces and emotion questionnaire.

Gerlach, C. (2009). Category-specificity in visual object recognition. Cognition, 111(3), 281-301. https://doi.org/https://doi.org/10.1016/j.cognition.2009.02.005

Ginsburg, A. P. (1984). A New Contrast Sensitivity Vision Test Chart. Optometry and Vision Science, 61(6).

https://journals.Iww.com/optvissci/Fulltext/1984/06000/A_New_Contrast_Sensitivity_Vision_ Test_Chart.11.aspx

Graham, N. L., Patterson, K., \& Hodges, J. R. (2000). The impact of semantic memory impairment on spelling: evidence from semantic dementia. Neuropsychologia, 38(2), 143-163.

Habekost, T., Petersen, A., Behrmann, M., \& Starrfelt, R. (2014). From word superiority to word inferiority: visual processing of letters and words in pure alexia. Cogn Neuropsychol, 31(5-6), 
413-436. https://doi.org/10.1080/02643294.2014.906398

Hackett, M. L., Yapa, C., Parag, V., \& Anderson, C. S. (2005). Frequency of depression after stroke: A systematic review of observational studies. Stroke, 36(6), 1330-1340.

https://doi.org/10.1161/01.STR.0000165928.19135.35

Hills, C. S., Pancaroglu, R., Duchaine, B. C., \& Barton, J. J. S. (2015). Word and text processing in acquired prosopagnosia. Annals of Neurology, 78(2), 258-271.

https://doi.org/10.1002/ana.24437

Jefferies, E., Patterson, K., Jones, R. W., \& Lambon Ralph, M. A. (2009). Comprehension of concrete and abstract words in semantic dementia. Neuropsychology, 23(4), 492-499.

https://doi.org/10.1037/a0015452

Langner, O., Dotsch, R., Bijlstra, G., Wigboldus, D. H. J., Hawk, S. T., \& van Knippenberg, A. (2010). Presentation and validation of the Radboud Faces Database. Cognition and Emotion, 24(8), 1377-1388. https://doi.org/10.1080/02699930903485076

Lefly, D. L., \& Pennington, B. F. (2000). Reliability and validity of the adult reading history questionnaire. J Learn Disabil, 33(3), 286-296.

Linksz, A. (1966). The Farnsworth Panel D-15 Test. American Journal of Ophthalmology, 62(1), 27-37. https://doi.org/https://doi.org/10.1016/0002-9394(66)91673-4

Martinaud, O., Pouliquen, D., Gerardin, E., Loubeyre, M., Hirsbein, D., Hannequin, D., \& Cohen, L. (2012). Visual Agnosia and Posterior Cerebral Artery Infarcts: An Anatomical-Clinical Study. PLoS One, 7(1), e30433. https://doi.org/10.1371/journal.pone.0030433

Neale, M. (1999). The Neale analysis of reading ability. ACER.

Nordfang, M., Uhre, V., Robotham, R. J., Kerry, S. J., Frederiksen, J. L., \& Starrfelt, R. (2019). A free and simple computerized screening test for visual field defects. Scandinavian Journal of Psychology, 60(4), 289-294. https://doi.org/10.1111/sjop.12546

Oldfield, R. C. (1971). The assessment and analysis of handedness: The Edinburgh inventory. Neuropsychologia, 9(1), 97-113. https://doi.org/http://dx.doi.org/10.1016/00283932(71)90067-4

Patterson, K., \& Hodges, J. R. (1992). Deterioration of word meaning: Implications for reading. Neuropsychologia, 30(12), 1025-1040. https://doi.org/https://doi.org/10.1016/00283932(92)90096-5

Roberts, D. J., Lambon Ralph, M. A., Kim, E., Tainturier, M.-J. J., Beeson, P. M., Rapcsak, S. Z., \& Woollams, A. M. (2015). Processing deficits for familiar and novel faces in patients with left posterior fusiform lesions. Cortex, 72(SI), 79-96.

https://doi.org/http://dx.doi.org/10.1016/j.cortex.2015.02.003

Roberts, D. J., Woollams, A. M., Kim, E., Beeson, P. M., Rapcsak, S. Z., \& Lambon Ralph, M. A. (2013). Efficient Visual Object and Word Recognition Relies on High Spatial Frequency Coding in the Left Posterior Fusiform Gyrus: Evidence from a Case-Series of Patients with Ventral OccipitoTemporal Cortex Damage. Cerebral Cortex, 23(11), 2568-2580. https://doi.org/10.1093/cercor/bhs224

Robotham, R. J. (2019). The Neuropsychology of Stroke in the Back of the Brain: Clinical and Cognitive Aspects. University of Copenhagen.

Robotham, R. J., \& Starrfelt, R. (2017). Comparing word and face recognition: an insoluble conundrum. Journal of Vision, 17(10), 1002. https://doi.org/10.1167/17.10.1002 
Robotham, R. J., \& Starrfelt, R. (2018). Tests of whole upright face processing in prosopagnosia: A literature review. Neuropsychologia, 121(March), 106-121.

https://doi.org/10.1016/j.neuropsychologia.2018.10.018

Shallice, T., \& Buiatti, T. (2011). Types of case series-the anatomically based approach: Commentary on M. F. Schwartz \& G. S. Dell: Case series investigations in cognitive neuropsychology. Cognitive Neuropsychology, 28(7), 500-514. https://doi.org/10.1080/02643294.2012.674012

Starrfelt, R., Gerlach, C., Habekost, T., \& Leff, A. P. (2013). Word-superiority in pure alexia. Behav Neurol, 26(3), 167-169. https://doi.org/10.3233/ben-2012-129002

Starrfelt, R., Habekost, T., \& Gerlach, C. (2010). Visual processing in pure alexia: A case study. Cortex: A Journal Devoted to the Study of the Nervous System and Behavior, 46(2), 242-255. http://ovidsp.ovid.com/ovidweb.cgi?T=JS\&CSC=Y\&NEWS=N\&PAGE=fulltext\&D=psyc6\&AN=201 0-01503-013

Starrfelt, R., Habekost, T., \& Leff, A. P. (2009). Too little, too late: Reduced visual span and speed characterize pure alexia. Cerebral Cortex, 19(12), 2880-2890.

http://ovidsp.ovid.com/ovidweb.cgi?T=JS\&CSC=Y\&NEWS=N\&PAGE=fulltext\&D=psyc6\&AN=200 9-21657-009

Starrfelt, R., \& Robotham, R. J. (2018). On the use of cognitive neuropsychological methods in developmental disorders. Cognitive Neuropsychology, 35(1-2). https://doi.org/10.1080/02643294.2017.1423048

Torfs, K., Vancleef, K., Lafosse, C., Wagemans, J., \& de-Wit, L. (2014). The Leuven Perceptual Organization Screening Test (L-POST), an online test to assess mid-level visual perception. Behav Res Methods, 46(2), 472-487. https://doi.org/10.3758/s13428-013-0382-6

Tranel, D., Logan, C. G., Frank, R. J., \& Damasio, A. R. (1997). Explaining category-related effects in the retrieval of conceptual and lexical knowledge for concrete entities : operationalization and analysis of factors. 35(10).

Vancleef, K., Acke, E., Torfs, K., Demeyere, N., Lafosse, C., Humphreys, G., Wagemans, J., \& de-Wit, L. (2015). Reliability and validity of the Leuven Perceptual Organization Screening Test (L-POST). J Neuropsychol, 9(2), 271-298. https://doi.org/10.1111/jnp.12050

Veale, J. F. (2014). Edinburgh Handedness Inventory - Short Form: a revised version based on confirmatory factor analysis. Laterality, 19(2), 164-177. https://doi.org/10.1080/1357650x.2013.783045

Wechsler, D. (2010). Wechsler Adult Intelligence Scale - Fourth UK Edition (WAIS IV - UK) (4th Editio). Pearson.

Woodhead, Z. V. J., Kerry, S. J., Aguilar, O. M., Ong, Y.-H., Hogan, J. S., Pappa, K., Leff, A. P., \& Crinion, J. T. (2018). Randomized trial of iReadMore word reading training and brain stimulation in central alexia. Brain, 141(7), 2127-2141. http://dx.doi.org/10.1093/brain/awy138

Yesavage, J. A., Brink, T. L., Rose, T. L., Lum, O., Huang, V., Adey, M., \& Leirer, V. O. (1983). Development and validation of a geriatric depression screening scale: a preliminary report. Journal of Psychiatric Research, 17(1), 37-49.

Yesavage, J. A., \& Sheikh, J. I. (1986). Geriatric Depression Scale (GDS) Recent Evidence and Development of a Shorter Version. Clinical Gerontologist, 5(1-2), 165-173.

https://doi.org/10.1300/J018v05n01_09 


\section{Role of the funding source}

This work was supported by a grant from the Independent Research Fund Denmark (Sapere Aude) to last author Randi Starrfelt (Grant no. DFF - 4180-00201). The council had no role in the collection, analysis, or interpretation of data; in the writing of the report; or in the decision to submit the article for publication.

\section{Conflict of interest}

The authors declare no conflict of interest.

\section{Acknowledgments}

We would like to thank Anders Petersen for help with test battery development. We would also like to thank Olivier Martinaud and Marlene Behrmann for sharing their experiments with us for the Back of the Brain project.

\section{Supplementary file}

Lists of stimuli for experiments in the Back of the Brain project that are not copyrighted are provided in the supplementary file: Robotham et al. 2021 BoB Methods Supplementary Material. 